\title{
Safety and efficacy of trial of labour after cesarean
}

\author{
Arihant Tater*, Swati Garg, Ashmita Jawa, Monika Jain
}

Department of Obstetrics and Gynaecology, Mahatma Gandhi Medical College and Hospital, Jaipur, India

Received: 25 September 2016

Accepted: 22 October 2016

\section{*Correspondence:}

Dr. Arihant Tater,

E-mail: dr.arihanttater@gmail.com

Copyright: (c) the author(s), publisher and licensee Medip Academy. This is an open-access article distributed under the terms of the Creative Commons Attribution Non-Commercial License, which permits unrestricted non-commercial use, distribution, and reproduction in any medium, provided the original work is properly cited.

\begin{abstract}
Background: In recent years, there are increasing numbers of cases which report for delivery after previous LSCS. Trial of labour after lower segment cesarean section can save them from repeat LSCS and its complications. Aim of study was conducted to evaluate the safety and efficacy of trial of labour after LSCS.

Methods: This is a prospective study carried out at Mahatma Gandhi Hospital. One hundred pregnant patients with previous LSCS giving informed consent for trial of labour after cesarean section (TOLAC) were enrolled. Case selection was done as per the ACOG guidelines. Continuous fetal and maternal monitoring done by WHO partograph and cardiotocography. If there appeared any indication for repeat cesarean then emergency LSCS was done.

Results: In this study, $80 \%$ of the enrolled patients delivered vaginally and $20 \%$ underwent repeat emergency LSCS. $2 \%$ of the enrolled patients underwent scar dehiscence. The patients in the active phase of labour on admission had more chances of successful vaginal birth after cesarean section (VBAC). Birth weight of more than 3000 grams is associated with lower rates of successful VBAC. There was no maternal mortality but $1 \%$ intrauterine fetal death due to scar rupture was there.

Conclusions: TOLAC is safe and the success rates are good. Proper selection of cases with adequate fetal and maternal monitoring is required. So, once cesarean always cesarean is not a true dictum.
\end{abstract}

Keywords: LSCS, Scars dehiscence, Trial of labour after cesarean section, Vaginal delivery after cesarean section

\section{INTRODUCTION}

“ONCE CAESAREAN ALWAYS A CAESAREAN" was the term given by CRAGIN in $1916 .{ }^{1}$ That era was of classical Caesarean section. Now the scenario has been changed and today we are performing lower segment caesarean section. The lower segment cesarean section gives us the liberty to give trial of labour after cesarean.

The rates of primary LSCS in increasing steadily and there is decreasing trend of vaginal birth after caesarean (VBAC), to decrease the rate of LSCS ACOG recommends that most pregnant women with previous 1 LSCS should be counselled for VBAC and trial of labour after cesarean (TOLAC). ${ }^{2}$

Appropriate clinical settings and properly selected group of patients can make the vaginal birth after caesarean (VBAC) safe and effective. Trial of labour after cesarean decreases rate of caesarean section and the morbidity associated with surgical intervention. In VBAC there is less blood loss, shorter duration of stay in hospital, less intrapartum and postpartum infections and it further decreases the economic burden on society and the individuals.

\section{Aim}

- To evaluate safety and efficacy of trial of labour after lower segment caesarean section.

\section{Objectives}

- To study and analyze various factors related to VBAC. 
- To study fetal and maternal outcome in VBAC.

\section{METHODS}

This is a prospective observational study conducted in department of Obstetrics and Gynecology at Mahatma Gandhi hospital, Jaipur after approval from institutional ethical committee.

A total no. of 100 patients fulfilling the selection criterion were selected after taking the written informed consent. The patients were both booked and unbooked cases. The booked cases are those who were on regular antenatal visits and the unbooked cases are those to came to the labour room directly during labour pains and had no history previous ANC visits in hospital.

Advantages of vaginal birth after caesarean were explained. They were explained about the risk of uterine rupture, fetal distress and need of immediate emergency LSCS anytime during TOLAC. Hematological, Serological investigation and USG were done if required. Continuous electronic monitoring and WHO partograph was plotted which gives the regular and qualitative assessment of maternal and fetal status. Four hourly per vaginal examination was done to assess the progress of labour and per vaginal examination is done earlier if required.

The signs for the scar dehiscence were monitored. Patient is provisionally prepared for emergency LSCS and the TOLAC was continued till the progress of labour is satisfactory. The patient is shifted for emergency repeat LSCS if there is unsatifactory progress scar tenderness fetal distress etc.

The patients were selected on the basis of ACOG guidelines.

\section{Inclusion criteria}

- $\quad$ Singleton pregnancy

- Gestational age >34 weeks

- Vertex presentation

- History of previous one LSCS

- Patient with spontaneous progress of labour.

\section{Exclusion criteria}

- $\quad$ Recurring indication for previous LSCS

- History of any other scar on uterus (myomectomy, hysterotomy)

- More than one LSCS

- Previous caesarean with vertical scar

Different factor responsible for VBAC were evaluated, the result was tabulated and statistically analyzed by using chi-square test.

\section{RESULTS}

In this study, $80 \%$ of the enrolled patients delivered vaginally amongst them $78(97.5 \%)$ delivered by spontaneous normal delivery and $2(2.5 \%)$ delivered by vaccum assisted vaginal delivery. $20 \%$ underwent repeat emergency LSCS. The most common cause of repeat emergency LSCS was non-progress of labour contributing in $50 \%$ of the cases.

Table 1: Effect of indication of previous LSCS on successful VBAC.

\begin{tabular}{|lllll|}
\hline $\begin{array}{l}\text { Indication } \\
\text { of previous } \\
\text { LSCS }\end{array}$ & $\begin{array}{l}\text { Successful } \\
\text { VBAC }\end{array}$ & $\begin{array}{l}\text { Emergency } \\
\text { LSCS }\end{array}$ & $\begin{array}{l}\text { Chi } \\
\text { Square } \\
\text { (df) }\end{array}$ & $\begin{array}{l}\text { P- } \\
\text { value }\end{array}$ \\
\hline $\begin{array}{l}\text { Maternal } \\
\text { causes }\end{array}$ & 39 & 14 & $\begin{array}{l}2.110 \\
(1)\end{array}$ & 0.146 \\
\hline Fetal causes & 41 & 6 & & \\
\hline
\end{tabular}

The $p$ value is $>0.005$ thus there is no significance of the cause of previous LSCS in success of VBAC.

The patients in the active phase of labour on admission had more chances of successful VBAC (Vaginal Birth after Cesarean Section). $90.76 \%$ of the patient admitted in active stage of labour delivered by successful VBAC. Only $60 \%$ of the patients in latent phase of labour delivered by VBAC.

Table 2: Effect of stage of labour on successful VBAC.

\begin{tabular}{|lllll|}
\hline $\begin{array}{l}\text { Stage } \\
\text { of } \\
\text { labour }\end{array}$ & $\begin{array}{l}\text { Successful } \\
\text { VBAC }\end{array}$ & $\begin{array}{l}\text { Emergency } \\
\text { LSCS }\end{array}$ & $\begin{array}{l}\text { Chi } \\
\text { Square } \\
\text { (df) }\end{array}$ & $\begin{array}{l}\text { P- } \\
\text { value }\end{array}$ \\
$\begin{array}{l}\text { Latent } \\
\text { phase }\end{array}$ & 21 & 14 & $\begin{array}{l}11.607 \\
(1)\end{array}$ & 0.000 \\
\hline $\begin{array}{l}\text { Active } \\
\text { phase }\end{array}$ & 59 & 6 & & \\
\hline
\end{tabular}

The patient admitted in active phase of labour have more chances to deliver vaginally. $p$ value is $<0.005$ that shows significance of stage of labour in success of VBAC.

93.4\% of the patients with new born weight $3 \mathrm{~kg}$ delivered by successful VBAC and the rates decreased with increasing new born weight to $50 \%$ in patients with newborn weight 3 to $3.5 \mathrm{~kg}$ and $12.5 \%$ in patient with newborn weight 3.5 to $4 \mathrm{~kg}$.

Table 3: Effect of neonatal weight on successful VBAC.

\begin{tabular}{|l|llll|}
$\begin{array}{l}\text { Neonatal } \\
\text { weight }\end{array}$ & $\begin{array}{l}\text { Successful } \\
\text { VBAC }\end{array}$ & $\begin{array}{l}\text { Emergency } \\
\text { LSCS }\end{array}$ & $\begin{array}{l}\text { Chi } \\
\text { Square } \\
\text { (df) }\end{array}$ & $\begin{array}{l}\text { P- } \\
\text { value }\end{array}$ \\
\hline$\leq 3 \mathrm{Kg}$ & 71 & 5 & 32.240 & 0.000 \\
\hline$>3 \mathrm{Kg}$ & 9 & 15 & $(1)$ & 0.000 \\
\hline
\end{tabular}

Birth weight of more than 3000 grams is associated with lower rates of successful VBAC. $p$ value is $<0.005$ that shows significance of birth weight in success of VBAC. 
The most appropriate interval between two deliveries for successful VBAC is 2 to 4 years when success rate is about $90 \%$. When interval decrease to 2 years. The successful VBAC rate decrease to $61.9 \%$.

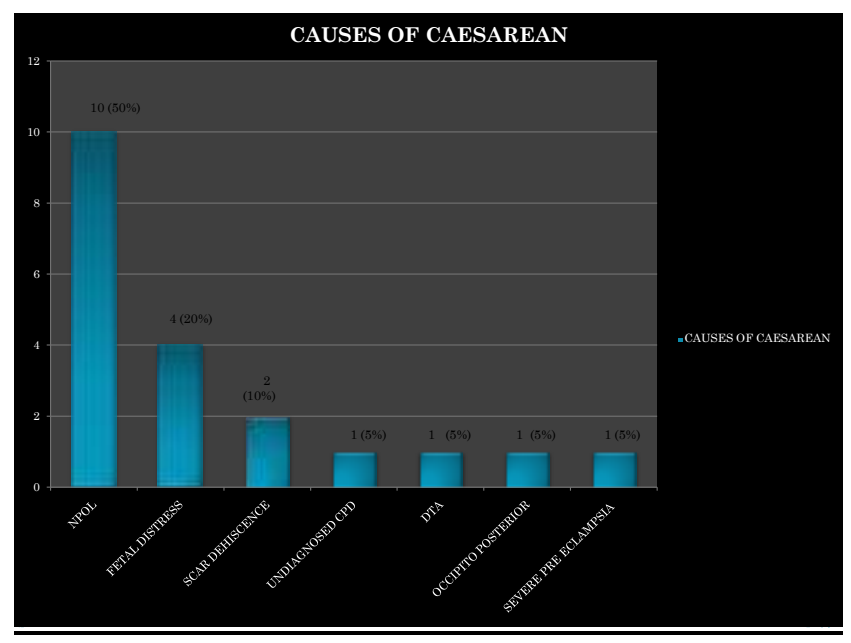

Figure 1: Causes of repeat emergency LSCS.

$2 \%$ of the enrolled patients underwent scar dehiscence. There was no maternal mortality but $1 \%$ intrauterine fetal death due to scar rupture was observed.

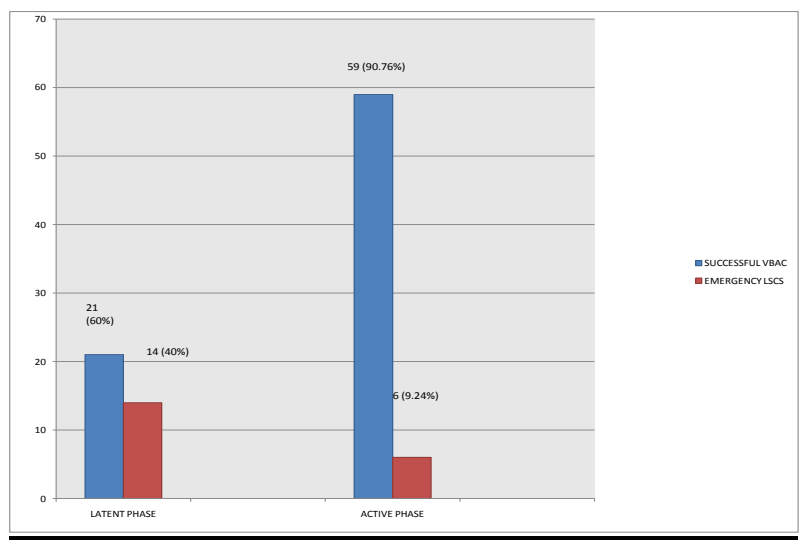

Figure 2: Stage of labour and success of VBAC.

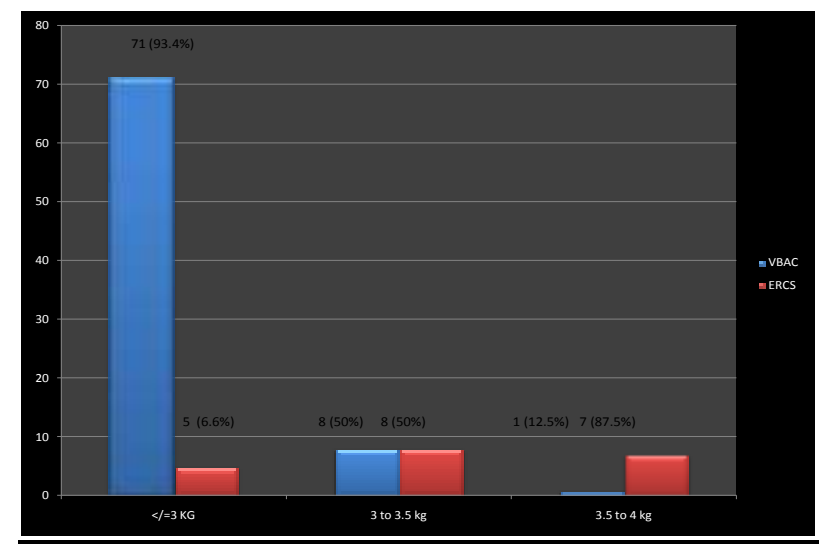

Table 4: Effect of birth interval on successful VBAC.

\begin{tabular}{|lllll|}
$\begin{array}{l}\text { Birth } \\
\text { interval }\end{array}$ & $\begin{array}{l}\text { Successful } \\
\text { VBAC }\end{array}$ & $\begin{array}{l}\text { Emergency } \\
\text { LSCS }\end{array}$ & $\begin{array}{l}\text { Chi } \\
\text { Square } \\
\text { (df) }\end{array}$ & $\begin{array}{l}\text { P- } \\
\text { value }\end{array}$ \\
\hline$\leq 2$ years & 21 & 13 & 9.049 & 0.003 \\
\hline$>2$ years & 59 & 7 & $(1)$ & 0.003 \\
\hline
\end{tabular}

The most appropriate interval between two deliveries for successful VBAC is 2 to 4 years. $p$ value $<0.005$ that shows significance birth interval on success of VBAC.

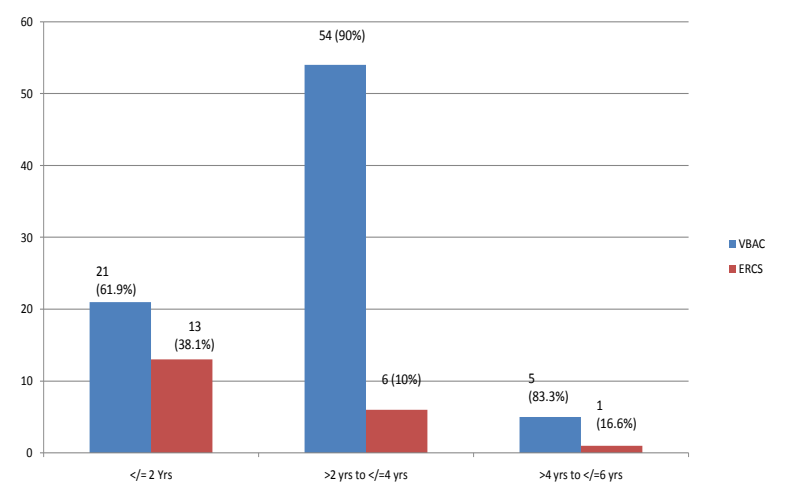

Figure 4: Interval between two deliveries and success of VBAC.

Table 5: Causes of previous LSCS and success of VBAC.

\begin{tabular}{|c|c|c|c|}
\hline $\begin{array}{l}\text { Indication of } \\
\text { previous LSCS }\end{array}$ & $\begin{array}{l}\text { No. of } \\
\text { cases }\end{array}$ & $\begin{array}{l}\text { Emergency } \\
\text { LSCS }\end{array}$ & $\begin{array}{l}\text { Successful } \\
\text { VBAC }\end{array}$ \\
\hline NPOL & 35 & $25(71 \%)$ & $10(29 \%)$ \\
\hline Fetal distress & 27 & $25(93 \%)$ & $2(7 \%)$ \\
\hline $\begin{array}{l}\text { Malpresentatio } \\
n \text { breech other }\end{array}$ & $\begin{array}{l}10 \\
5\end{array}$ & $\begin{array}{l}8(80 \%) \\
4(80 \%)\end{array}$ & $\begin{array}{l}2(20 \%) \\
1(20 \%)\end{array}$ \\
\hline Pre-eclampsia & 7 & $7(100 \%)$ & 0 \\
\hline Eclampsia & 1 & 0 & $1(100 \%)$ \\
\hline $\begin{array}{l}\text { Severe } \\
\text { oligohyd- } \\
\text { roamnios }\end{array}$ & 5 & $4(80 \%)$ & $1(20 \%)$ \\
\hline $\begin{array}{l}\text { Cephalopeliv- } \\
\text { disproportion }\end{array}$ & 10 & $7(70 \%)$ & $3(30 \%)$ \\
\hline
\end{tabular}

\section{DISCUSSION}

As the rates of cesarean sections are increasing day by day a large number of patients come with the pregnancy after one or more cesarean delivery. These cases come under high risk group as they have scarred uterus and the scar is at risk of rupture during pregnancy and during labour and this can lead to serious complications to mother and fetus.

In this study, $80 \%$ of selected patients delivered vaginally that is consistent with Riva and Teich, Dayal V, Allahabadia, Phelan et al and O Sullivan. ${ }^{3-7}$

Figure 3: Neonatal weight and success of VBAC. 
The study shows that the commenest indication of elective repeat cesarean section was non progress of labour $(50 \%$ which is consistent with Archna Maurya et al. $(48 \%){ }^{8}$ The study shows the cause of previous LSCS do not make a significant difference in success of trial of labour after cesarean $\mathrm{p}$ value $>0.146$.

Patient admitted in active phase of labour as more chances of successful VBAC $\mathrm{p}$ value $<0.05$ which shows stage of labour making significant difference in success of VBAC. In 1997 Flamm et al study demonstrated the patient with the dilation $4 \mathrm{~cm}$. had an $86 \%$ rate of VBAC. ${ }^{9}$ In the presence study neonatal rate had significance role in success of trial of labour after cesarean $p$ value $<0.05$ which is consistent with Archana Maurya et al. ${ }^{8}$ Doshi et al. $p$ value $<0.02$ whereas study done by birara and geberhibot shows that there is no association between birth weight of baby in success of VBAC. ${ }^{10}$

In the present study interval between two deliveries had significant role in success of TOLAC $p$ value $<0.003$ if the interval is less than 2 years the rate of LSCS were high and if the interval is more than 2 years the rate of elective repeat cesarean section were less the result were consistent Archana Maurya et al p value $<0.001$ and Doshi et al $\mathrm{p}$ value $<0.01$. $^{8,10}$

So there is no such rule that the patient can be delivered vaginally or should go for elective repeat LSCS after primary LSCS, each and every patient should be evaluated and line of treatment should be individualised.

Present study shows that appropriate clinical settings and properly selected group of patients can make the trial of labour after cesarean safe and effective.

\section{ACKNOWLEDGEMENTS}

First and foremost I would like to thanks all mighty God who blessed me to come till here. I am extremly grateful to my guide Dr. Swati Garg for her emence support and guidance during the study. I am thankful to my parents, my betterhalf, my colleagues and to all those who were directly or indirectly related to this study and supported me during the study.

Funding: No funding sources

Conflict of interest: None declared

Ethical approval: The study was approved by the Institutional Ethics Committee

\section{REFERENCES}

1. Cragin EB. Conservatism in Obstetrics. N Y Med J. 1916;104:1-3.

2. Sachs BP, Kobelin C, Castro MA. The risk of lowering the cesarean delivery rate. $\mathrm{N}$ Engl J Med. 1999;340:54-7.

3. Riva HL, Teich JC. Vaginal delivery after caesarean section. Am J Obstet Gynaecol. 1961;81:501.

4. Dayal V. Trial of vaginal delivery in cases of single previous cesarean section. J Obstet Gynecol. 1985;35:445-50.

5. Allahabadia GN, Ambiye VR, Shanbaug AM. Vaginal birth following caesarean section. J Obstet Gynecol India. 1989;39:782-6.

6. Phelan JP, Clark SL, Diaz F, Paul RH. Vaginal birth after caesarean. Am J Obstet Gynecol. 1987; 157:1510-5.

7. Sullivan OMJ, Fumia F, Holsinger K, McLeod AG. Vaginal delivery after caesarean section. Clin Perinatol. 1981;8:131-43.

8. Maurya A, Manik A. Study of factors associated with success of vaginal birth after previous one caesarean section. Sch. J. App. Med. Sci., 2016;4(1C):210-3.

9. Flamm BL, Geiger AM. Vaginal birth after cesarean delivery: an admission scoring system. Obstet Gynecol. 1997 Dec;90(6):907-10.

10. Doshi HU, Jain RK, Vazirani AA. Prognostic factors for successful vaginal birth after cesarean section: Analysis of 162 cases. J Obstet Gynaecol India. 2010;60:498-502.

Cite this article as: Tater A, Garg S, Jawa A, Jain M. Safety and efficacy of trial of labour after cesarean. Int J Reprod Contracept Obstet Gynecol 2016;5:4335-8. 